\title{
ABORDAGENS PSICOSSOCIAIS SOBRE A PRIMEIRA FASE DA PANDEMIA DO NOVO CORONAVÍRUS NO BRASIL
}

\author{
Benedito Medrado ${ }^{1}$, Jorge Luiz Cardoso Lyra da Fonseca', \\ Simone Maria Hüning ${ }^{2}$, Anita Guazelli Bernardes ${ }^{3}$, \\ Laura Vilela e Souza ${ }^{4}$, Lupicinio Iñíguez Rueda ${ }^{5}$, \\ Maria Lucia Chaves Lima ${ }^{6}$ e Mariana Prioli Cordeiro ${ }^{7}$ \\ ${ }^{1}$ Universidade Federal de Pernambuco, Recife/PE, Brasil \\ ${ }^{2}$ Universidade Federal de Alagoas, Maceió/AL, Brasil \\ ${ }^{8}$ Universidade Católica Dom Bosco, Campo Grande/MS, Brasil. \\ ${ }^{4}$ Universidade de São Paulo, Faculdade Medicina Ribeirão Preto, Ribeirão Preto/SP, Brasil. \\ ${ }^{5}$ Universitat Autònoma de Barcelona - UAB, Barcelona, Espanha \\ ${ }^{6}$ Universidade Federal do Pará, Programa de Pós-Graduação em Psicologia, Belém/PA, Brasil \\ ${ }^{7}$ Universidade de São Paulo, Departamento de Psicologia Social e do Trabalho, \\ Instituto de Psicologia, São Paulo/P, Brasil
}

Para proteger a humanidade é preciso nos afastar dela! Com esse chamado, a Organização Mundial da Saúde (OMS) nos clama ao “isolamento social”, em um dos períodos mais críticos da história mundial, que têm afetado profundamente nossos modos de interação e de produção, alterando dinâmicas simbólicas e materiais.

Quando começamos a escrever esse texto, em 01/05/2020 (feriado do dia do/a trabalhador/a), as entidades oficiais responsáveis pelo monitoramento da pandemia do novo coronavírus já registravam quase 3,5 milhões de pessoas diagnosticadas com o $S A R S-C o V-2$ (conhecido como "novo coronavírus") e quase 250 mil mortos/as. A despeito da grande subnotificação, o Brasil já era o primeiro da América Latina em número de casos e estava entre os 10 países com maior incidência do vírus, com quase 100 mil casos e mais de 6.000 mortes (7\%), além de mais de 1.500 óbitos em investigação, segundo dados oficiais do Ministério da Saúde (Brasil, 2020a).

Hoje (26/08/2020), passados menos de 4 meses, o cenário é ainda mais preocupante e, certamente, quando você estiver lendo esse texto, os números serão ainda maiores. $\mathrm{O}$ Brasil hoje já é o segundo país do mundo em número de casos de pessoas diagnosticadas com o SARS-CoV-2 e de mortes por Covid-19, registrando, formalmente, 3.669.995 casos de pessoas contaminadas e 116.580 mortes, ou seja, um número maior do que o quantitativo global de morbidades e mortalidades registrado em maio. Hoje, no mundo inteiro, já são quase 24 milhões de pessoas contaminadas e quase 820 mil mortes (Brasil, 2020b).

A revista Psicologia \& Sociedade resistiu, inicialmente, em produzir um dossiê sobre essa pandemia, tendo em vista tratar-se de um fenômeno complexo, sobre o qual, neste momento, ainda temos mais questionamentos do que capacidade de produzir conhecimentos metodologicamente densos e eticamente responsáveis. Pareceu-nos, em princípio, uma proposta pouco sensível e oportunista, com risco de resultar em produções superficiais. 
Porém, embora ainda consideremos prematuro falar, de forma ampla e profunda, sobre os efeitos da pandemia, em uma perspectiva psicossocial crítica, resolvemos fazer um recorte cuidadoso, focalizando o conjunto de controvérsias importantes que se adensaram nesta primeira fase da pandemia no Brasil - particularmente em relação aos jogos políticos, disputas de versões, práticas preventivas e dinâmicas interpessoais mobilizadas (ou potencializadas) neste início da pandemia - e que justificariam a publicação deste dossiê. Neste sentido, convidamos a comunidade científica a produzir artigos que possam nos ajudar não a compreender, mas talvez a melhor organizar nossas dúvidas e questões fundamentais, que têm alimentado nossos debates nesta primeira fase da pandemia.

Neste momento, aqui definido como "primeira fase da pandemia”, que compreende especialmente o primeiro semestre de 2020, temos operado, no Brasil, com maior ou menor resistência, a difícil e necessária medida de prevenção baseada no isolamento social (alguns dizem ser apenas físico) orientado por entidades e profissionais baseados em protocolos da OMS (WHO, 2020a; WHO, 2020b).

\section{Panorama desafiador}

As hashtags imperativas "\#fiqueemcasa" e "\#usemascara” viralizaram (para usar um termo ironicamente apropriado), em forma de campanhas sanitárias, nas redes sociais em meio a disputas de versões sobre origem, diagnóstico, imunização e tratamento da doença; insegurança generalizada em relação às informações (especialmente no tocante ao número efetivo de casos de contaminação, adoecimento e morte); orientações sanitárias que mudam no ritmo da expansão do número de casos; canais diversos de mídia disputando versões; repertórios midiáticos de grandes corporações alinhados a projetos políticos e econômicos capitalista comuns (ou não) e práticas discursivas machistas e patriarcais que colocam em relevo a ordem produtiva em detrimento da ética do cuidado e da vida.

Hoje, o quadro epidemiológico da pandemia, no Brasil, põe em relevo problemas sociais há muito denunciados pelos movimentos sociais e pelo campo de estudos e pesquisas em psicologia social. No caso brasileiro, a pandemia reproduz a desigualdade social resultante de processos e dinâmicas de colonialidade e segregação racial. Não por acaso, hoje, o maior número de casos e as maiores taxas de letalidade são registradas entre as populações negras, nas diferentes regiões do nosso país.

Além disso, em países como o Brasil e Estados Unidos, em que os governantes não apresentam uma clara política de prevenção e tratamento e preferem, de forma irresponsável, ignorar a gravidade do problema, a pandemia toma contornos ainda mais preocupantes. Assim, no campo da dinâmica pública, este período tem sido também marcado por controvérsias políticas em um cenário pré-eleitoral; gestões públicas e projetos político-econômicos em choque; ascensão e queda de um ministro da saúde que, apoiado em princípios, diretrizes e orientações de especialistas em saúde pública, confrontava abertamente discursos e práticas do representante máximo do poder executivo neste país; vacância temporária de representante do ministério da saúde; desrespeito e desinvestimento progressivo na produção científica nacional, especialmente aquela voltada para o campo das Ciências Humanas e Sociais; (des)governos, cinismos, argumentos medievais, descasos (PRADO, 2020). 
Neste cenário, do ponto de vista programático, das políticas públicas e práticas coletivas, explicitam-se também problemas sociais crônicos, sistemas de saúde à beira do colapso (já diagnosticado há tempos); tecnologias de necropolítica e práticas coloniais operadas a olho nu, gerontocídio, acentuação da desigualdade social marcadas por classe e raça. Em contrapartida, emergem práticas solidárias da sociedade civil organizada, possibilidades artísticas e culturais de resistência e episódios que apresentam uma ressurreição da natureza, graças à restrição da circulação de humanos.

Do ponto de vista das relações interpessoais, o imperativo "fique em casa" explicitou também problemas relativos à dinâmica considerada privada. Algumas pessoas já moravam sós e passaram a viver sós. Outras passaram a conviver 24 horas com pessoas com quem só se encontravam ao acordar, no fim do dia e nos fins de semana, quando muito. Ressaltam-se aqui as dificuldades estruturais relacionadas à moradia da maioria da população brasileira e o fato da casa ser, para algumas pessoas, espaço de violência e opressão. Não por acaso, registramos incremento de agravos à saúde mental e da violência doméstica e familiar baseada em gênero e sexualidade (WENHAM; SMITH; MORGAN, 2020).

Para os que têm acesso à tecnologia avançada de comunicação, novos desafios se conformaram. Potencializaram-se convivências e interações mediadas por dispositivos on-line aproximando distâncias e potencializando encontros, mas também, conflitos. As ferramentas remotas, por sua vez, possibilitam intensificar o trabalho (especialmente o chamado "intelectual”) e a competir com os afazeres domésticos e esses passaram a existir para quem apenas usufruía do seu produto. Isso sem contar o verdadeiro bombardeio de lives, "vidas", em meio a espetacularização da morte entre corpos ensacados, campos de vala comum e containers funerários.

$\mathrm{E}$, aos poucos, fomos ampliando nosso vocabulário anglo-saxão como a delivery, fake news, lockdown e tantas outras práticas expressas em termos incorporados na vida comum quase como se fora língua local; e "actantes" (LATOUR, 1994) passam a se performar em diferentes materialidades (máscaras, álcool em gel 70\%, óculos de proteção, macacões que se assemelham aos usados em operações envolvendo material radioativo ou EPI da apicultura etc.). Em meio a tudo isso, uma constatação e uma grande dúvida, sem respostas prontas ou fáceis: o que (ou como) seremos depois de tudo isso?

Neste campo profícuo de controvérsias, considerando a importância de leituras psicossociais críticas para a produção de conhecimento sobre momentos críticos como o que estamos vivendo, a revista Psicologia \& Sociedade (Gestão 2020-2023) lançou uma convocatória para reunir textos que nos ajudassem a problematizar essas leituras. 


\section{Sobre a construção do Dossiê}

Nos últimos três meses, parte da equipe de editores/as da revista se dedicou à elaboração deste Dossiê, para o qual foram recebidas propostas, em formato de resumos ampliados (mínimo 1.000 e máximo 1.500 palavras, incluindo o corpo do texto e as referências bibliográficas) em que sejam apresentados: 1) delimitação do problema/tema; 2) objetivos do texto; 3 ) referencial teórico e método; 4) resultados, análises e considerações breves que dialoguem com as questões suscitadas nos objetivos. Esses resumos foram avaliados pela equipe editorial da revista quanto à adequação à proposta do Dossiê e conformidade com o escopo da revista.

Diante do grande número de propostas recebidas e considerando o número limitados de textos que compõem um dossiê, desenvolvemos uma avaliação comparativa entre os manuscritos, considerando os seguintes critérios de avaliação: 1) a estrutura concisa e coerente do texto, conforme padrões usuais da comunicação científica; 2) contribuição singular da proposta ao campo de estudos sobre o qual versa o Dossiê, com delimitação precisa do objeto de estudo/pesquisa, corpus e estratégias de análise bem delineadas e leituras coerentes com a fundamentação teórica apresentada; 3) natureza mais crítico-analítica do que descritivo-opinativa na apresentação das análises; 4) relação direta com o tema do Dossiê, e não de forma indireta ou tangencial.

Neste sentido, em respeito à tradição de nossa revista, que se consolida a partir da resistência a formas individualistas e abordagens experimentais de pesquisa em psicologia social, privilegiamos textos que: 1) dialogavam criticamente com a literatura e os debates contemporâneos em relação ao tema abordado e ao campo de estudos em psicologia social (no âmbito das ciências humanas e sociais) e não apenas arrolassem textos e autores; 2) cuja natureza fosse explicitamente analítica, com solidez de argumentos e não apenas uma descrição de procedimentos, resultados e análises e 3) que apresentassem contribuição inequívoca do manuscrito ao campo de estudos sobre o qual versa o manuscrito e sobre o campo teórico que aborda. Para desempate, adotou-se como critérios: 1) o nível de desenvolvimento da proposta apresentada em comparação com as demais; 2) a variabilidade de temas para o conjunto do Dossiê; e 3) a busca de equilíbrio na distribuição regional dos/ as autores/as.

Os/as autores/as dos resumos aprovados nesta primeira etapa foram orientados/as, então, a submeter seu texto completo, na plataforma da revista, seguindo as mesmas normas de uma submissão regular. Assim, todos as propostas aprovadas nesta primeira etapa seguiram procedimento de avaliação assim estruturado: primeiro momento, uma equipe de assessores/as editoriais, sob supervisão dos/as editores/as, procedeu a conferência da adequação do manuscrito às normas da revista; no segundo momento, apenas os textos aprovados no primeiro momento foram enviados para os/as editores/as, que realizaram a avaliação de escopo e de qualidade; e no terceiro momento, os textos aprovados pelos/as editores/as no segundo momento foram encaminhados para o processo de avaliação por pares, preservando a identidade dos autores e consultores (double blind review). 


\section{Conteúdo}

No total, recebemos 59 resumos, dos quais selecionamos 19 para submissão de manuscritos. A partir da avaliação dos/as pareceristas ad hoc, aprovamos 17 artigos, os quais organizamos em duas partes que passaram a compor o dossiê "Abordagens psicossociais sobre a primeira fase da pandemia do novo coronavírus no Brasil”.

Na primeira parte, são apresentados textos que versam sobre questões éticas, políticas, conceituais e históricas que são acionadas a partir do advento da pandemia. Nessa seção, foram incluídos textos sobre: gestão de riscos em contextos de incerteza (Mary Jane Spink); dilemas éticos sobre o cuidado (Juan Guillermo Figueroa-Perea); narrativas sobre a morte durante a gripe espanhola e a Covid-19 no Brasil (Rosineide Cordeiro e Luciana Kind); metáforas que acionam dinâmicas e modos de subjetivação (Mario Carvalho, Anna Clara Luz, Bruna Paulino e Camilla Ferreira); narrativas entre ciência e política (André Luiz Machado das Neves e Breno de Oliveira Ferreira); saúde mental e modos outros de viver (Maria Angelica de Melo Rente e Emerson Elias Merhy).

Na segunda parte, reunimos textos que nos provocam reflexões sobre dimensões da vida em sociedade profundamente afetadas pela pandemia e nos brindam com debates sobre desafios, fundamentos e horizontes. Nesta seção foram incluídos textos sobre: contradições estruturantes e emergentes nas relações sociais no Brasil que se expressam na dinâmica do trabalho doméstico remunerado (Maria Betânia Ávila e Verônica Ferreira); implicações da pandemia para o mundo do trabalho (Kelen Christina Leite); paradoxos do isolamento na dinâmica dos afetos entre indígenas Sateré-Mawé, do Amazonas (Bader Sawaia, Renan Albuquerque e Flávia Busarello); dinâmicas subjetivas e intersubjetivas da relação eu-outro(a)-mundo próprias à experiência íntima de confinamento domiciliar (Marina Pinheiro e Roberta Mélo); contribuições da contação de histórias para a saúde mental no contexto da pandemia de Covid-19 (Jaileila Menezes, Síria Botelho, Roseane Amorim da Silva, Antônio Santos, Daniela Souza Leão, Victoria Canales, Ítala Silva, Helen Silva e Bruno dos Santos); a ratificação de uma política de morte no sistema prisional brasileiro (Jaqueline Sério da Costa; Johnny Clayton da Silva; Eric Brandão e Pedro Paulo Bicalho); dinâmicas de gênero entre a casa e a guerra (Lisandra Espíndula Moreira, Júlia Alves, Renata Oliveira e Claudia Natividade); vulnerabilidade programática e violência contra a mulher (Brisa Campos, Bruna Borba e Vera Paiva); práticas políticas de afirmação da vida acionadas a partir de acolhimento psicológico e afetos (Laura Quadros, Cláudia Cunha e Anna Paula Uziel); controvérsias do uso de máscaras por homens negros em uma sociedade marcada por racismo e regime necropolítico (Lucas Gabriel Santos e Rosa Pedro); impacto da quarentena e Covid-19 na comunidade trans (Manoel Antônio dos Santos, Wanderlei Oliveira, Érika Oliveira-Cardoso).

No conjunto desses textos, a pandemia se revela como a ponta de um grande e profundo iceberg. Apesar do pouco tempo entre a convocatória e a publicação desses textos, consideramos que o produto final resultou em uma bela publicação, com relevância histórica, marcada pela pluralidade de perspectivas e por uma densa produção de questionamentos que podem contribuir, sobremaneira, para seguirmos ampliando nossos olhares sobre problemas sociais densos que criam restrições ao projeto por justiça social em nosso país. 


\section{Referências}

BRASIL. Ministério da Saúde (2020a). Brasil registra 91.589 casos de coronavírus e 6.329 mortes pela doença. Disponível em https://www.saude.gov.br/noticias/agencia-saude/46821brasil-registra-91-589-casos-de-coronavirus-e-6-329-mortes-pela-doenca. Acessado em 28/08/2020.

BRASIL. Ministério da Saúde (2020b). Covid 19. Painel Coronavírus. Disponível em https://covid.saude.gov.br/ Acessado em 26/08/2020.

LATOUR, Bruno (1994). Jamais fomos modernos. Rio de Janeiro: Editora 34.

PRADO, Bruna (2020). COVID-19 in Brazil: “So what?”. The Lancet, 395, v. 10235, p. 1461. WENHAM, Clare; SMITH, Julia \& MORGAN, Rosemaryon (2020). COVID-19: the gendered impacts of the outbreak. The Lancet, 395 (10227), pp. 846-848.

World Health Organization [WHO].(2020a, February 3). 2019 Novel Coronavirus (2019-nCoV): Strategic Preparedness and Response Plan, SPRP.

http://www.who.int/docs/default-source/coronaviruse/srp

World Health Organization [WHO]. (2020b, March 19). Considerations for quarantine of individuals in the context of containment for coronavirus disease (COVID-19): Interim guidance. https://www.who.int/publications/i/item/considerations-for-quarantine-ofindividuals-in-the-context-of-containment-for-coronavirus-disease-(covid-19) 
BENEDITO MEDRADO

https://orcid.org/0000-0002-1085-5024

E-MAIL: beneditomedrado@gmail.com

JORGE LUIZ CARDOSO LYRA DA FONSECA

https://orcid.org/0000-0002-5381-2059

E-MAIL: jorglyra@gmail.com

SIMONE MARIA HUNING

https://orcid.org/0000-0001-8080-7733

E-MAIL: simone.huning@ip.ufal.br

\author{
ANITA GUAZELLI BERNARDES \\ https://orcid.org/0000-0003-4742-6036 \\ E-MAIL: anitabernardes1909@gmail.com
}

LAURA VILELA E SOUZA

https://orcid.org/0000-0003-0732-8175

E-MAIL: laura.psisoc@gmail.com

LUPICINIO IÑÍGUEZ RUEDA

https://orcid.org/OOOO-0002-1936-9428

E-MAIL: lupicinio.iniguez@uab.es

MARIA LUCIA CHAVES LIMA

https://orcid.org/OOOO-0003-3062-2399

E-MAIL:marialuciacl@gmail.com

MARIANA PRIOLI CORDEIRO

https://orcid.org/0000-0002-5523-5099

E-MAIL: mpriolicordeiro@usp.br 